\section{Comment on "Small Bilaterian Fossils from 40 to 55 Million Years Before the Cambrian"}

Chen et al. (1) reported coelomate bilaterians from the $\sim 600$-million-year-old Doushantuo phosphorites in southern China. Such a find might meet some common expectations of small, simple bilaterians emerging after the worldwide glaciations of the Neoproterozoic. The interpretation is not well founded, however, because it fails to take into full account taphonomy (changes in the organism after death) and diagenesis (changes in the sediment after deposition). sented by Chen et al. (1) represent a common mode of preservation of microfossils in phosphatic sediments, including those of the Doushantuo (2) and the overlying Dengying (3) formations: a more or less undeformed outer membrane; a shrunken, irregular internal mass, often connected to the outer membrane by occasional threads or sheets; and thin layers of diagenetic mineral, commonly apatite (calcium phosphate), lining the surfaces of the resulting cavities (Fig. 1). Such diagenetic minerals usually have a characteristic crystallographic structure normal to the encrusted surface. Chen et al. have provided no information on the structure of the published figures show clear evidence of diagenetic origin:

(i) The layers have a regular banding between the specimens but consistent within the individual specimens, whether counted from the outer wall inward or from the central body outward. In the direction toward
The specimens predue to the growth direction the layers they interpret as cellular, but even of color and thickness that is different what they describe as the coelomic lumen, Chen et al. showed a thickness sequence of approximately $2+2+5 \mu \mathrm{m}$ [figure $1 \mathrm{~A}$ in convex features directed toward the putative coelomic lumen. This is a typical feature of diagenetic crusts, in which irregularities on the overgrown surface serve as nuclei for spherulitic fans (Fig. 1, B to E).

(iii) The layers show typical cavityfilling geometry. The outermost layer is missing in narrow spaces where earlier growth left no room for it [compare, for example, figure 1B-1, lower part, in (1) and Fig. 1C, arrow, in this comment].

(iv) The layers show conspicuous dark lines perpendicular to the
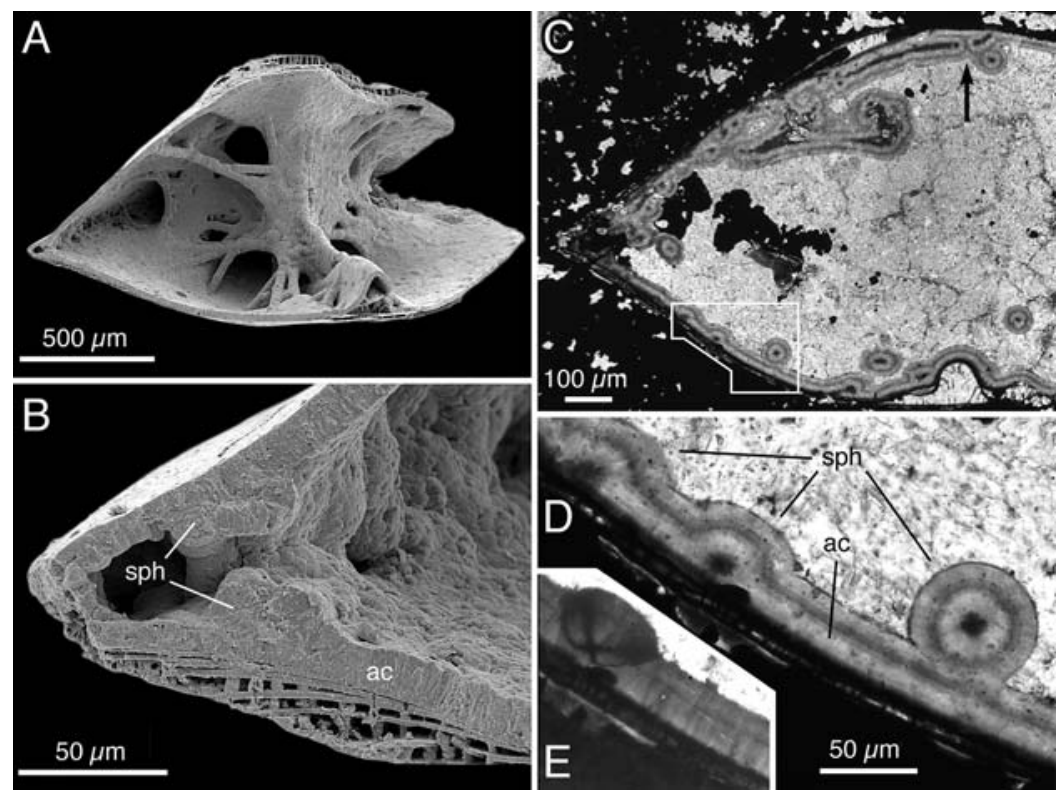

Fig. 1. Lingulate brachiopod Linnarssonia from Middle Cambrian phosphatized limestone in south Sweden (locality Kvasa, Scania). (A and B) Scanning electron microscopy pictures of broken specimen. Swedish Museum of Natural History (SMNH) Br138245. Posterior parts of dorsal (bottom) and ventral (top) valves preserved, together with shrunken soft tissues still connected by stretched threads or sheets to shell, mainly to areas of strong epithelial adherence (sites of muscle attachment). All internal cavities are lined by diagenetic apatite consisting of surface-normal acicular crystallites (ac), in places forming spherulitic fans (sph). (C to E) Thin section of similarly preserved specimen in limestone matrix. SMNH X1520 [also shown in figure 3, D and E, in (7)]. Plane-polarized light (C and D) and crossed nicols (E); frame in $(C)$ indicates position of (D). Note layered structure of diagenetic lining, ordered crystallography [see polarizing cross in spherulite in (E)], inwardly convex spherulitic fans growing over irregularities on encrusted surface, absence of later-formed layer in narrow spaces [arrow in (C)], and surface-normal lineations (corresponding to direction of acicular apatite crystallites) crossing boundary between generations of diagenetic lining. This kind of diagenetic lining, also exemplified in (2), (3), and (6), is analogous to the purported cellular layers of lining, also exemplified in (2), (3), and (6), is analogous to the
the Doushantuo bilaterians as interpreted by Chen et al. (1).

(1)]; one of $3+5+5 \mu \mathrm{m}$, with the first layer considerably darker than the subsequent two [figure 1B in (1)]; and one of $2+$ $5 \mu \mathrm{m}$ [figure $1 \mathrm{C}$ in (1)]. This pattern defies biological explanation but is easily explained as representing two to three generations of diagenetic overgrowth (Fig. 1, C to E).

(ii) Rather than being sinuously folded, as would be expected from deformed tissue layers, the layers consistently have their surfaces. Chen et al. (1) refer to these as "cellular structure preserved." Cell walls may indeed be preserved in these sequences (3-5), typically by internal encrustation by diagenetic minerals (6). Surfaceperpendicular lines within diagenetic crusts, however, more likely represent fine cracks propagated along the directions of surface-normal acicular crystallites. The fact that the lines in the specimens depicted by Chen et al. [for example, figure 2, C and $\mathrm{D}$, in (1)] commonly continue across the boundaries between the layers is strong evidence that they are propagating cracks rather than cell boundaries.

Chen et al. concede that one thin partial coating of the layers is of diagenetic origin. They do not address, however, any of the clear indications of diagenesis in the main layers, but simply assert that they represent cellular layers because they have been consistently observed in independent specimens of the same morphological organization and similar dimensions. In view of the fact that the supposedly bilaterian specimens have been selected from among 50,000 to 100,000 microfossils, the perceived consistencies are far from impressive. The supposed mouth and anus are reported from two specimens each. The putative pharynx, gut, and coeloms are reported from all 10 selected specimens, but these features will be present by construct if specimens are selected that happen to have the internal lump of 


\section{TECHNICAL C OMMENT}

shrunken matter touching or connected with the outer wall in two places in the plane of section. No information is given, other than conjecture, on the three-dimensional structure of the figured specimens, and there is no account of the variability of any of the 50,000 to 100,000 microfossils not selected as bilaterians. As a result, even a reader unacquainted with diagenesis would be hard put to identify any morphological regularities in the specimens.

Similarly, the "regularly spaced pits" on the outer surface, interpreted as sensory organs, appear to represent irregularities formed by mineral growths penetrating the surface of the original microfossil and accentuated by typical spherulite fans in the cavity-lining layers (see, for example Fig. 1D, upper left, and E, in this comment). Numerous such structures exist in the specimens depicted by Chen et al.-for example one specimen [figure $1 \mathrm{~B}$ in (1)] shows at least a dozen of them along the periphery and half that number around the area that Chen et al. interpret as the gut - and the ones selected as pits differ in no important way from the others. Even the designated pits are not regularly spaced as claimed, as can be easily seen from the figured specimens.

When taphonomy and diagenesis are taken into account, the evidence that these fossils preserve minute coelomate bilaterians disappears. The objects illustrated and described by Chen et al. (1) may well be eukaryotic microfossils, but their reconstructed morphology as bilaterians is an artifact generated by cavities being lined by diagenetic crusts. The appearance of the fossils now has little resemblance to that of the living organisms that generated them.

To paraphrase Theodosius Dobzhansky: Nothing in paleontology makes sense except in the light of taphonomy and diagenesis.

Stefan Bengtson* Department of Palaeozoology Swedish Museum of Natural History Box 50007

SE-104 05 Stockholm, Sweden
Graham Budd

Department of Earth Sciences,

Palaeobiology

Norbyvägen 22

SE-752 36 Uppsala, Sweden

*To whom correspondence should be addressed:

E-mail: stefan.bengtson@nrm.se

\section{References}

1. J.-Y. Chen et al., Science 305, 218 (2004); published online 3 June 2004 (10.1126/science.1099213).

2. S. Xiao, X. Yuan, A. H. Knoll, Proc. Natl. Acad. Sci. U.S.A. 97, 13684 (2000)

3. Z. Yue, S. Bengtson, Lethaia 32, 181 (1999)

4. S. Xiao, Y. Zhang, A. Knoll, Nature 391, 553 (1998).

5. S. Bengtson, Z. Yue, Science 277, 1645 (1997).

6. S. Bengtson, in The New Panorama of Animal Evolution, Proceedings of the 18th International Congress of Zoology, A. Legakis, S. Sfenthourakis, R. Polymeni, M. Thessalou-Legaki, Eds. (Pensoft, Sofia, Bulgaria, 2003), pp. 289-300.

7. S. Bengtson, Lethaia 9, 185 (1976).

10 June 2004; accepted 16 October 2004 